
Digitized by the Internet Archive in 2011 with funding from University of Toronto 


CONTRIBUTIONS OF THE ROYAL ONTARIO MUSEUM DIVISION OF ZOOLOGY AND PALAEONTOLOGY

No. 46

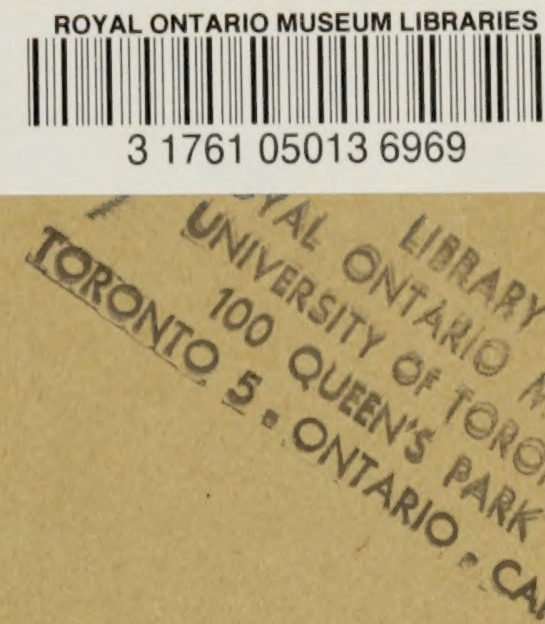

THE AFFINITIES OF THE NORTH AMERICAN SPECIES OF GOMPHUS AS REVEALED BY THE GENITALIA (ODONATA, GOMPHIDAE)

By

E. M. Walker

100 Queen's Park TORONTO, CANADA

March 15, 1957 

CONTRIBUTIONS OF THE ROYAL ONTARIO MUSEUM DIVISION OF ZOOLOGY AND PALAEONTOLOGY

No. 46

THE AFFINITIES OF THE NORTH AMERICAN SPECIES OF GOMPHUS AS REVEALED BY THE GENITALIA

(ODONATA, GOMPHIDAE)

By

E. M. Walker

100 Queen's Park

TORONTO, CANADA

March 15, 1957 



\title{
THE AFFINITIES OF THE NORTH AMERICAN SPECIES OF GOMPHUS AS REVEALED BY THE GENITALIA (ODONATA, GOMPHIDAE)
}

\author{
By E. M. WALKer
}

\section{INTRODUCTION}

During the summer of 1954 I was engaged in a study of the Canadian species of the odonate genus Gomphus, my objective being the preparation of the section on this genus for volume 2 of The Odonata of Canada and Alaska. The main problem that confronted me was that of the natural relationships of the species and the question as to whether this large and unwieldy genus should be subdivided. This problem had, of course, been attempted before with some measure of success by Needham, who from the time of his first publication in 1897 to his latest paper in 1948 based his classification on characters of both the mature insects and the nymphs or larvae.

It is unnecessary to repeat the history of the attempts that have been made to solve this difficult problem, since this has been set forth in detail in Needham's last paper (1948). Nearly all the important steps were taken by Needham himself and yet many of the species have been shifted from one subgenus to another by various writers. It is evident, therefore, that the subgenera or genera into which Gomphus has been divided since the time of Hagen have not all been defined to the satisfaction of every worker. One of the subgenera, in fact, that which has been considered as Gomphus s.s., typified by G. vulgatissimus (L.) of Eurasia, is admitted by Needham to be a composite group.

Fraser (1940) expresses his difficulty of clearly recognizing Needham's subgenera of Gomphus, having found that the characters used in defining these subgenera were "variable complexes of similar characters" and that in practice these characters break down. Thus he says "venational differences appear in the same species and quite often in the opposite wings of the same specimen."

My preliminary studies were made at my summer residence with limited material and works of reference. I spent much time in studying the characters that had already been employed in classifying the species of Gomphus, giving particular attention to the hamuli but, although much was learned of the varied forms of these structures, I was unable to correlate them with variations in other organs. I came to the conclusion that no system of classification could be based primarily on the structure of the hamuli alone.

My attention turned next to the penis, which was described in some detail by Needham in his paper of 1948, particularly the large basal 
part, which has generally been known as the vesicle, although never found to contain sperm capsules, as stated by Tillyard (1917).

I had made considerable progress in the study of the penis itself before I became acquainted with Fraser's (1940) work in the same field, this paper having been brought to my attention by Dr. P. P. Calvert after my return to Toronto. Fraser was led to undertake this study "to ascertain if the penile organ offered any characters by which the large number of species included at present in the genus Gomphus Leach could be split up into smaller and more wieldy genera." Eventually, however, he found it desirable to extend his study to include the entire family Gomphidae. His general conclusion was "that the taxonomic value of the penes of the Gomphidae is largely doubtful."

My study was of course very restricted as compared with Fraser's. I found that, in the first place, the validity of Needham's subgenera Arigomphus, Gomphurus and Stylurus was confirmed by the study of the penes, but that the subgenus Gomphus was, as Needham admitted, a composite including some species with penes closely approaching those of the other subgenera.

There are two main types of penes found in the genus Gomphus, differing chiefly in the length of the terminal segment, the glans with its appendages the flagella.

One type of penis has a short open glans and a short terminal filament, the other an elongated tubular glans and generally a pair of long flagella. These two types may be called, for convenience, the short and long types respectively. They will be more fully characterized later.

There are also two main types of the large basal segment of the penis, generally known as the vesicle but termed by Needham the peduncle, since it is not a true vesicula seminalis. These two types of vesicle were named by Needham the "split-loaf" and the "cleftpyramidal" types and in the main they are correlated with the two types of penis as classified by the length of the glans and flagella. This was to be expected, since it is one of the functions of the vesicle to protect in its median groove the delicate terminal parts of the penis, the glans and flagella, in the resting state.

Intergradation between the two types of glans and their associated parts occurs only in a few species, which are at present placed in the subgenus Gomphus, and it is among the same species of Gomphus that we find intermediate types of vesicle, although the parallelism is not perfect, since the species of the subgenus Hylogomphus, in which the penis is of the short type, also possess an intermediate form of vesicle.

There is a similar but imperfect division of the subgenera of Gomphus, based on the female genitalia or vulvar lamina. Except in the subgenus Hylogomphus all American species of the genus Gomphus, in which the penis belongs to the short type, have vulvar laminae which are more than twice as broad as long, whereas those 
species in which the penis is of the long type possess vulvar laminae, which are longer than broad. It may be noted that the type species of Gomphus, G. culgatissimus (L.), resembles Hylogomphus in the above character.

\section{The Genitalia of Gomphus}

MALE GENITALIA

Since the genitalia, especially those of the male, appear to be of primary importance in the phylogeny and classification of the species of the genus Gomphus, it is necessary to consider their structure in greater detail.

The general structure of the gomphid penis has been described by Fraser (1940) and Needham (1948). It will only be necessary here to consider certain features, chiefly those of taxonomic value.

The basal segment, known as the vesicle (Pl. I:1 [V] or peduncle has already been mentioned. It arises from the anterior part of the sternum of the third abdominal segment and extends far forward into the genital fossa, underlying the sternum of segment 2. Supported by a broad base is the main part of the vesicle, known as the hood. This is a saccular structure of variable form and is usually more or less cordate or bilobed in front owing to the presence of a median cleft formed by the infolding of the wall and serving to lodge and protect the delicate terminal parts of the penis. Below (as we examine the insect with the ventral side up), the vesicle is funnel-shaped, narrowing rapidly to its passage into the second segment of the penis or stem ( $\mathrm{S}$ ) (Fraser), a short tube with firm walls, which is connected with the vesicle by a membranous ginglymus joint. It is abruptly bent upward and curved backward. Its passage is continued into the median segment (M), which is of comparable length and calibre. It leaves the stem posteriorly at about a right angle. Fraser suggested that its "function is probably to give greater mobility to the penis and possibly it serves also as a release valve, permitting the penis to collapse and be withdrawn; the tiny aperture on its upper surface suggests such a mechanism." The penis, however, is apparently blind, being merely an erectile organ, which is extended by pressure from behind, arising in the vesicle.

The underside of the middle segment is semimembranous and projects backward under the fourth segment in the form of a compressed pouch or horn, the prepuce (PR). The fourth and last segment, continuing the direction of the middle segment, terminates in the semimembranous glans, which is tubular at base, but opens distally, bearing at the apex one or two filaments or flagella. At the base of the glans there is usually a tubular, neck-like region, which widens proximad to form a spreading collar (C), whose basal margin in many species projects. There may also be lateral preputial folds, which are loose 

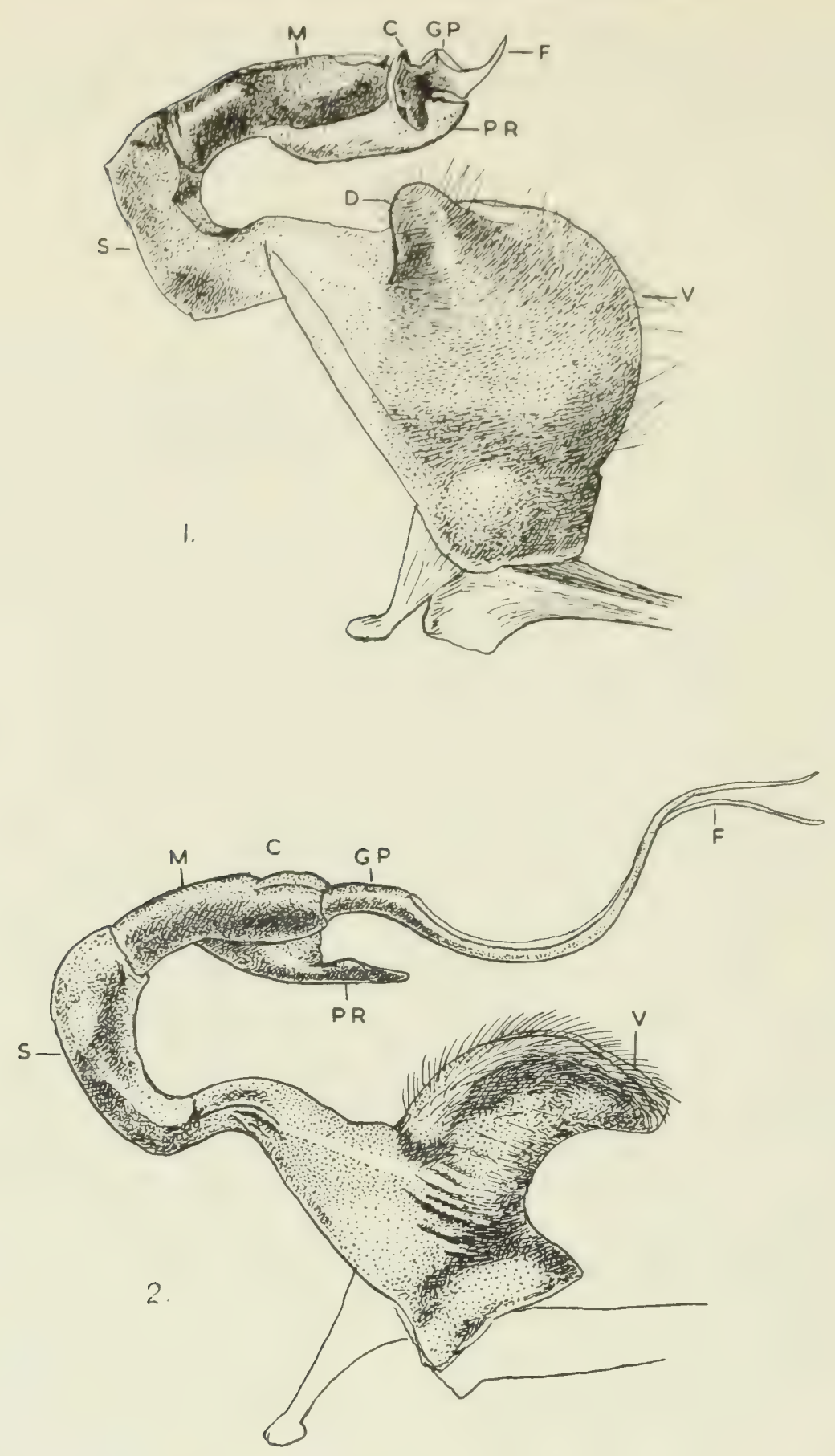

Plate I. Types of penes. 1. Short type in Gomphus lividus Selys. 2. Long type in Gomphus fraternus Say. Left lateral view of both. (For abbreviations used on plates, see p. 24.) In 1 the vesicle $(\mathrm{V})$ belongs to the split-loaf type, in 2 to the cleft-pyramidal type.

membranous folds arising from the distal margin of the middle segment on each side.

\section{Two Types of Penis}

As already mentioned there are two types of penis in Gomphus, which have been termed the short and the long types. The short type is the more common and probably the older type, as it occurs in 

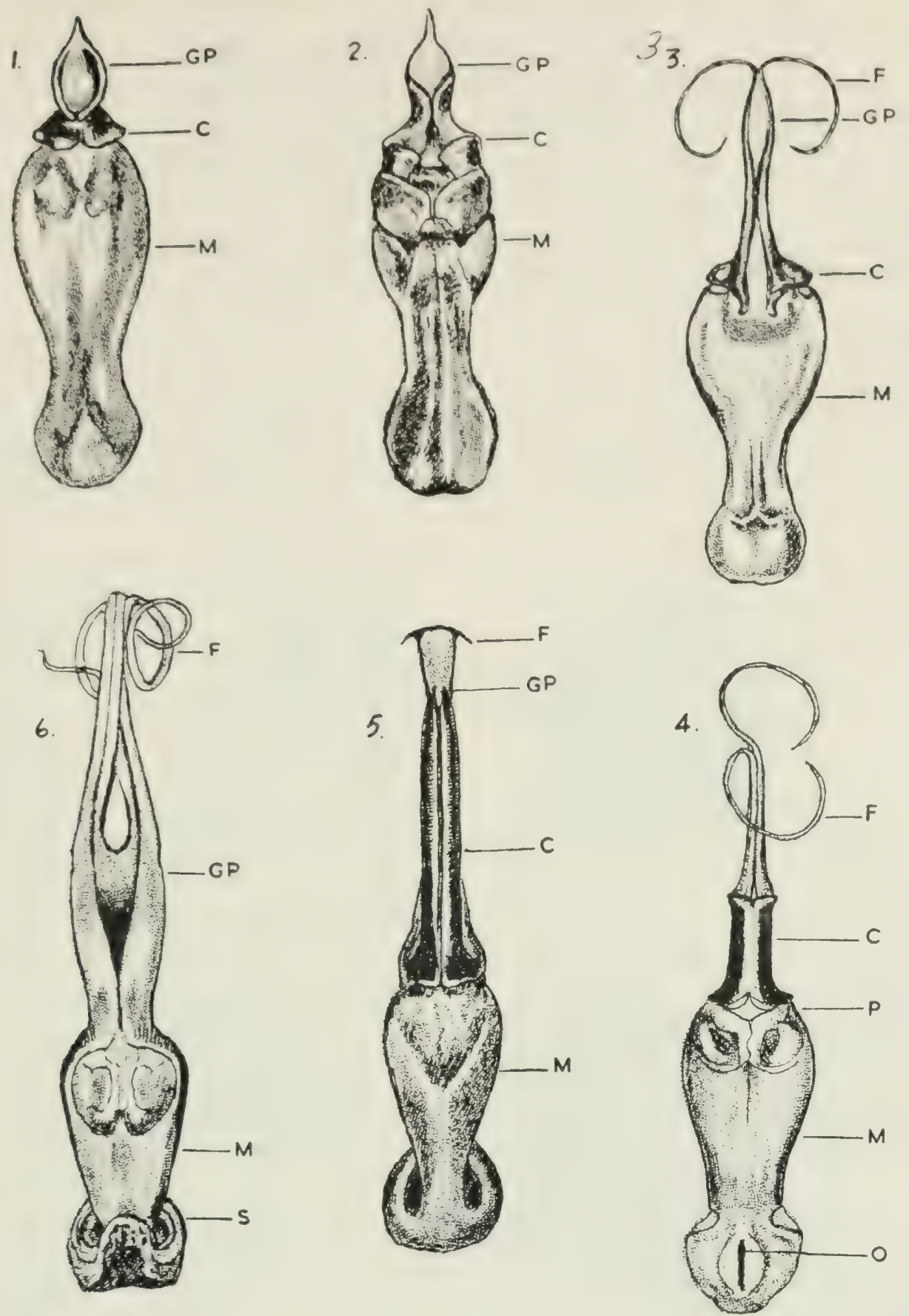

Plate II. Gomphus: terminal segments (3 and 4) of penis. 1. notatus; 2. brevis; 3. spicatus; 4. fraternus; 5. furcifer; 6. villosipes.

some other genera besides Gomphus. It may be illustrated by Gomphus lividus Selvs (PI. I:1). It is characterized by the form of the glans (GP), which resembles a trowel or boat in form, being open above, closed at the ends, with the apex tilted and bearing a short needle-like filament $(\mathrm{F})$. The neck-like part at the base is a very short constriction but widens proximally into the collar (C), a pair of spreading, sclerotized pads connecting the glans with the median segment.

The long type of penis is well illustrated by Gomphus fraternus 
(PI. I:2), which is typical both in the elongation of the glans and flagella and in the form of the vesicle that is usually associated with this type of penis. The glans (GP) is a cylindrical tube, with a constriction, whose median suture is formed by the meeting and fusing of the originally lateral edges. The two flagella (F) are long and flexible. The prepuce (PR) is slender and more sclerotized than in Gomphus lividus, resembling a spine rather than a pouch, but this is not an invariable feature of the long penis.

\section{Variations in the Hood}

The relation between the apical parts of the penis and the hood is very close since the hood serves as a protective sheath for the glans and flagella. Thus we find that the short type of penis is usually associated

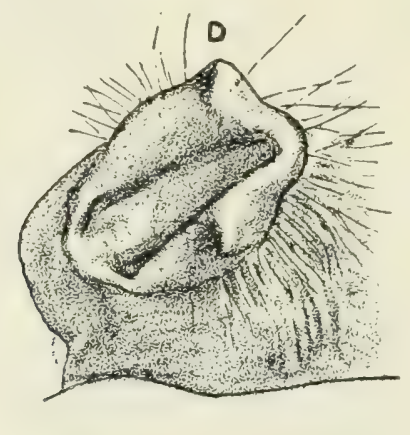

I. A
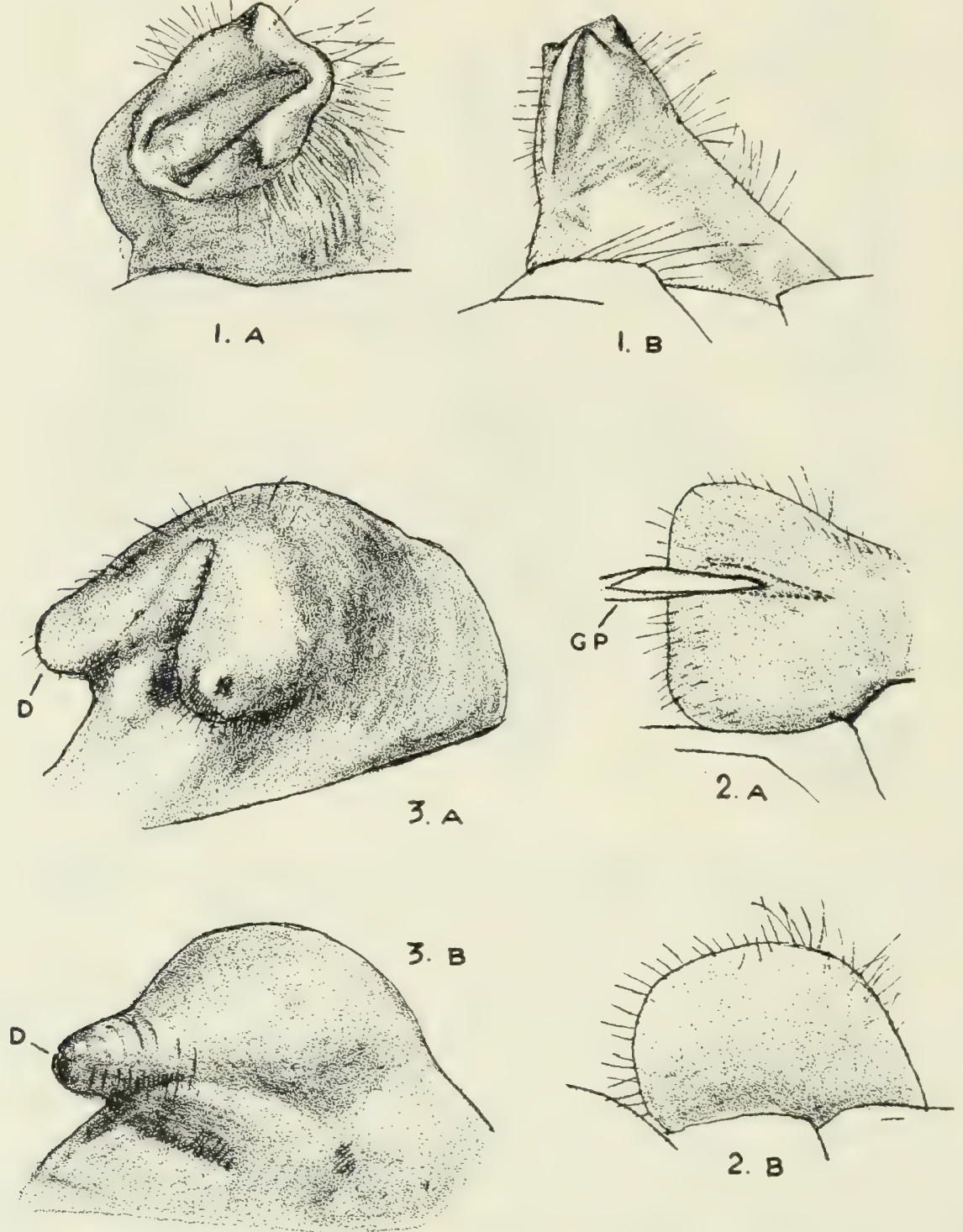

Plate III. Hoods of vesicles, A antero-dorsolateral, B lateral views. 1. Gomphus brevis (bilobate type); 2. G. exilis, intermediate type; 3. lividus (split-loaf type). 
with the split-loaf type of hood, whereas the long type is generally found with the cleft-pyramidal hood.

The split-loaf hood (PI. III:3) has the form of a rounded loaf or an inflated sac. It is very convex behind but bilobed or cordate in front, owing to the infolding of the wall to form the median cleft or groove. This is a short and rather narrow cleft, not extending far back and with no specially hairv parts. Sometimes there is a pair of lateral diverticula, as in Gomphus lividus (PI. I:1[D]) but this feature is not typical of the split-loaf hood and is more often absent. The general surface may bear a thin scattering of soft hair but is never very hairy. The split-loaf hood is found in most species of the subgenus Gomphus and nearly all of the species of Stylurus.

The cleft-pyramidal hood ( Pl. IV:2,3) is characterized by the great development of the median cleft, which extends from end to end, even passing around the distal end of the hood to the rear, so that the hood becomes bilobed behind as well as in front and the posterior surface is concave instead of convex, as it is in the split-loaf hood. The thickened lips of the median cleft are very hairy. The cleft-pyramidal hood is found in all species of Gomphurus and Arigomphus and in one of Gomphus s.s.

Other types of hoods intermediate between the two described above are found in a few of the species of Gomphus s.s. and in all of Hylogomphus (Pls. III, IV). The general form is a subcylindrical or pyramidal sac with the anterodorsal surface bisected by a narrow and little elongated cleft, which usually terminates distally in a slightly projecting fold or lobe, and on each side of the cleft, nearer the proximal end, is a short diverticulum. The edges of the cleft are slightly thickened but not rolled out as in the cleft-pyramidal hood and the hairs are soft and generally distributed. This intermediate form of hood may be termed the bilobate type from the presence of the two lobes or diverticula.

This type is represented in G. (Gomphus) descriptus (Pl. IV:1) and G. (Hylogomphus) brevis (PI. III:1). It is essentially similar in these two species, although in descriptus the general form is subcylindrical, in brevis pyramidal, tapering from a broad base, with the cleft surface somewhat longer and more sloping. In brevis, however, this type of hood is associated with the short penis, instead of the long, as in descriptus. The hood of G. exilis, also Gomphus s.s., is near the splitloaf type but lacks the large inflated rear extension, on which the name "split-loaf" is based. The diverticula are reduced to low conical prominences.

The split-loaf type of hood is easily derived from the bilobate type. In some species of the subgenus Gomphus, e.g., lividus, it differs little from the latter type, except that it appears to be inflated, the posterior wall in particular being very convex. The lateral diverticula are 

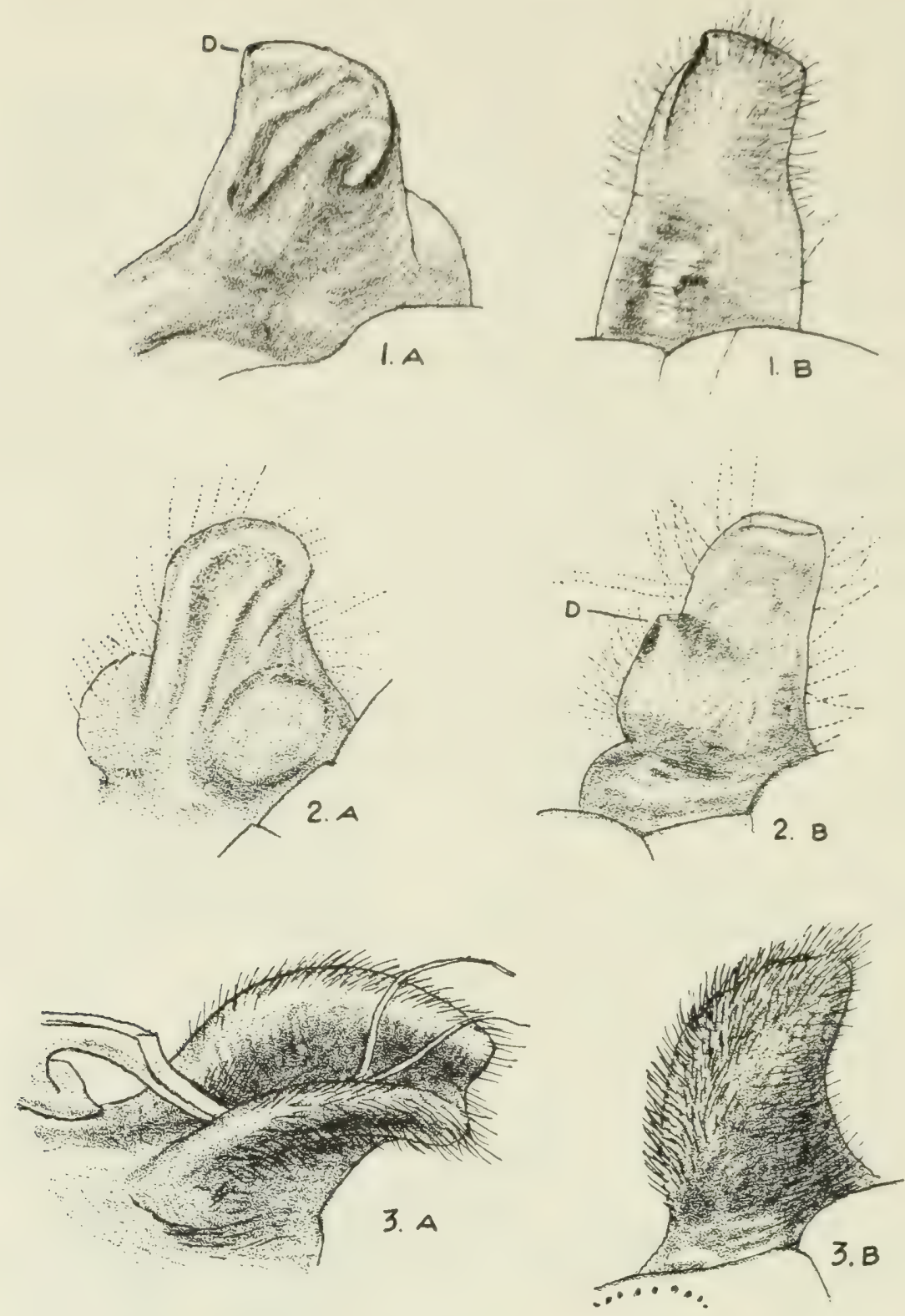

Plate IV. Hoods of vesicles. A antero-dorsolateral, B lateral views. 1. Gomphus descriptus (bilobate type); 2. G. borealis (cleft-pyramidal type); 3. G. fraternus (cleft-pyramidal type).

present (Pl. I:1; Pl. III:3), but there is no median prominence at the distal end of the cleft. This cleft is more widely open behind and the hair is sparser. Most of the species of Gomphus s.s. have this type of hood but with little or no trace of the diverticula. In Stylurus (Pl. V:2; Pl. VIII:2) the split-loaf hood is also present in nearly every species, the only exception known to us being $S$. intricatus, in which the hood is very short and its posterior surface is somewhat concave. This is, however, evidently a secondary modification of the convex form that is typical of Stylurus.

The cleft-pyramidal hood has also evolved from the bilobate type but in an entirely different manner. Only one species of the subgenus 

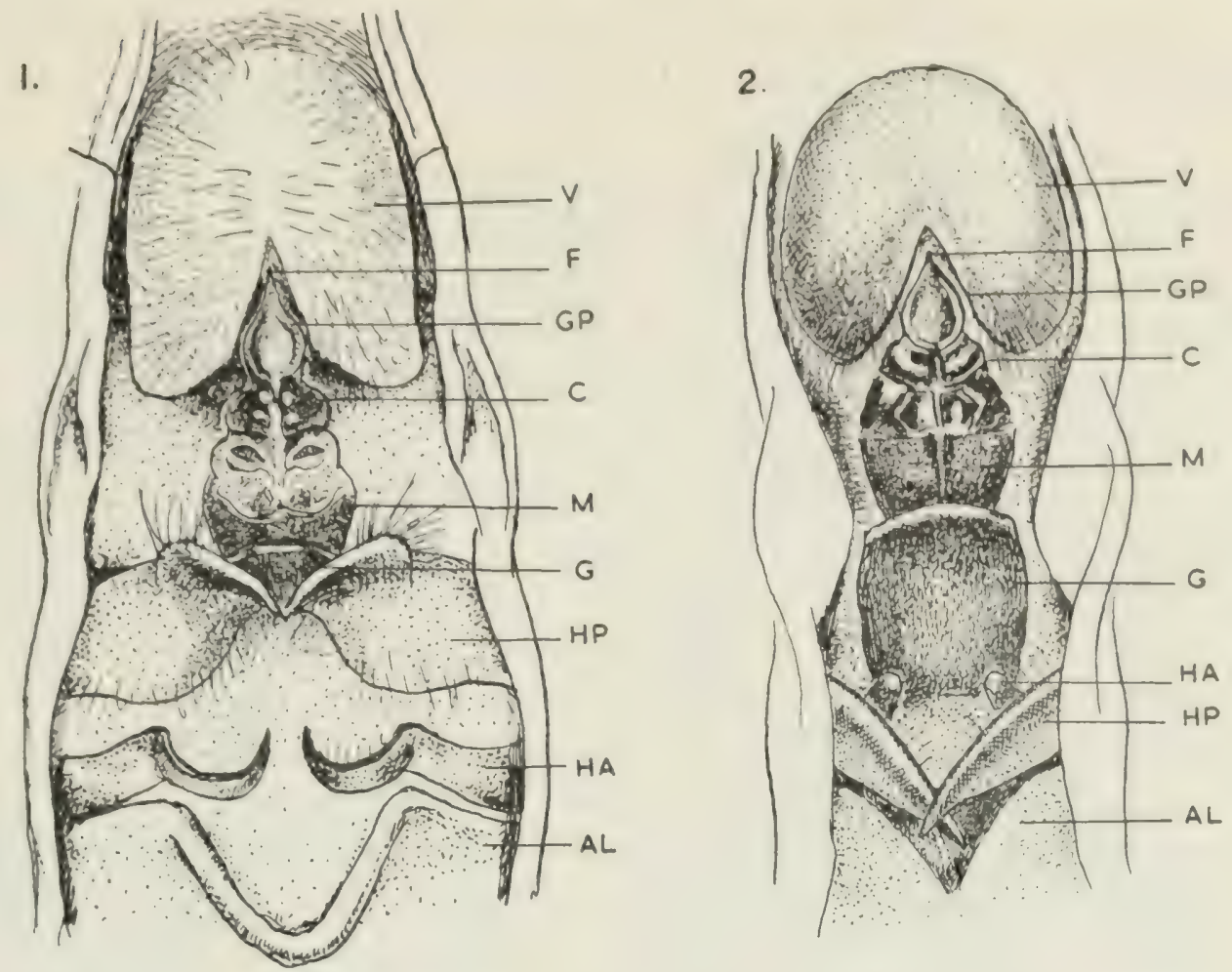

Plate V. Male genitalia in situ: 1. Gomphus lividus;2. G. notatus.

Gomphus possesses a hood that could be called a cleft-pyramidal one. This species is G. borealis $\mathrm{Ndm}$. whose nearest relative is $\mathrm{G}$. descriptus Banks, the hood of which belongs to the bilobate type. That of $G$. borealis (PI. IV:2) has a much longer and more open median cleft, which extends the entire length of the hood and has thickened lips very suggestive of a species of Gomphurus. It is, however, less distinctly bilobed in front, and the hair, which is abundant but not very coarse, resembles that of Arigomphus rather than Gomphurus. In the typical hood of the cleft-pyramidal variety there is no trace of the diverticula, but in the hood of $G$. borealis there is a prominence on each side, near the anterior end, on which vestiges of these diverticula may be seen. This is the only example I have seen of a hood that bridges the gap between the primitive bilobate and the cleft-pyramidal type.

\section{Variations in Penial Structure in the Subgenera of Gomphus}

Subgenus Gomphus. This is a composite group in which the taxonomic characters of other groups meet and intergrade. In most of the species the penis is of the short type and the hood is of the split-loaf type. In others the penis approaches the long type or definitely belongs to it but is usually not quite as specialized as those belonging to the subgenera Arigomphus and Gomphurus. On the basis of genitalia alone it would seem desirable to subdivide this group but in other respects the subgenus Gomphus seems too uniform both in the adult and the 
larval stages to warrant such a division. It is usually undesirable to subdivide even a subgenus on the basis of a single character or even one from each sex.

Gomphus grastinellus Selys, G. confraternus Selys and G. quadricolor Walsh are examples of species of the Gomphus group which approach Stylurus in the structure of the penis including the vesicle; G. lividus Selys also, except that the vesicle, though inflated, has a pair of lateral diverticula or as in the bilobate type of vesicle.

In Gomphus exilis Selys (Pl. VI:1) the glans is considerably elongated, terminating in paired flagella, but these are coherent, through their entire length, although the glans is tubular for only a relatively short distance. The hood is very short and is similar to the split-loaf type, but is scarcely at all inflated and the posterior surface is but little convex. Traces of the two pouches are indicated by the bluntly pointed anterolateral angles. This species is probably the most definitely intermediate of all the subgenus. In G. spicatus (Pl. VI:2) the penis is more definitely of the long type, having two long flexible flagella, separate throughout their length, and a tubular glans like that of Gomphurus, though less prolonged and with the collar less clearly demarcated. The hood is of the bilobate type with the pouches small, though more distinct than in exilis. Two other species of this group with long penes are G. descriptus Banks and G. borealis Needh. G. descriptus is similar to spicatus but with still longer penial structures and a higher, more columnar hood of the bilobate type. Borealis is like exilis in having the flagella coherent, but they are much longer and much more tapering. This is the only species of the subgenus Gomphus which may be said to have a cleft-pyramidal hood ( $\mathrm{Pl}$. IV:2). It is peculiar in having anterolateral protuberances with vestiges of lateral diverticula, but the general form, with its concave posterior surface is unmistakably that of the cleft-pyramidal type of vesicle.

Subgenus Hylogomphus (PI. III:1). This is a group of five or six species, in which the penis is of the short type but the vesicle is of the bilobate type, similar to that of certain species of the subgenus Gomphus, but associated in that group with the long type of penis. The vesicle is more pyramidal than in Gomphus and more inclined rearward but is essentially similar to that of Gomphus.

Although the subgenus Hylogomphus was based mainly on renational characters, these are very slight, and its chief claim to subgeneric rank is in the elongation of the vulvar lamina, which somewhat resembles that of Gomphurus, and in the nymphal characters which are also similar to these of Gomphurus. The type of penis, however, is the opposite to that found in all the species of Gomphurus.

Subgenus Gomphurus (PI. VII:1). In this group the penis is of the long type and very like those of G. spicatus and descriptus, except that the tubular part of the glans is longer, more sharply defined both in 


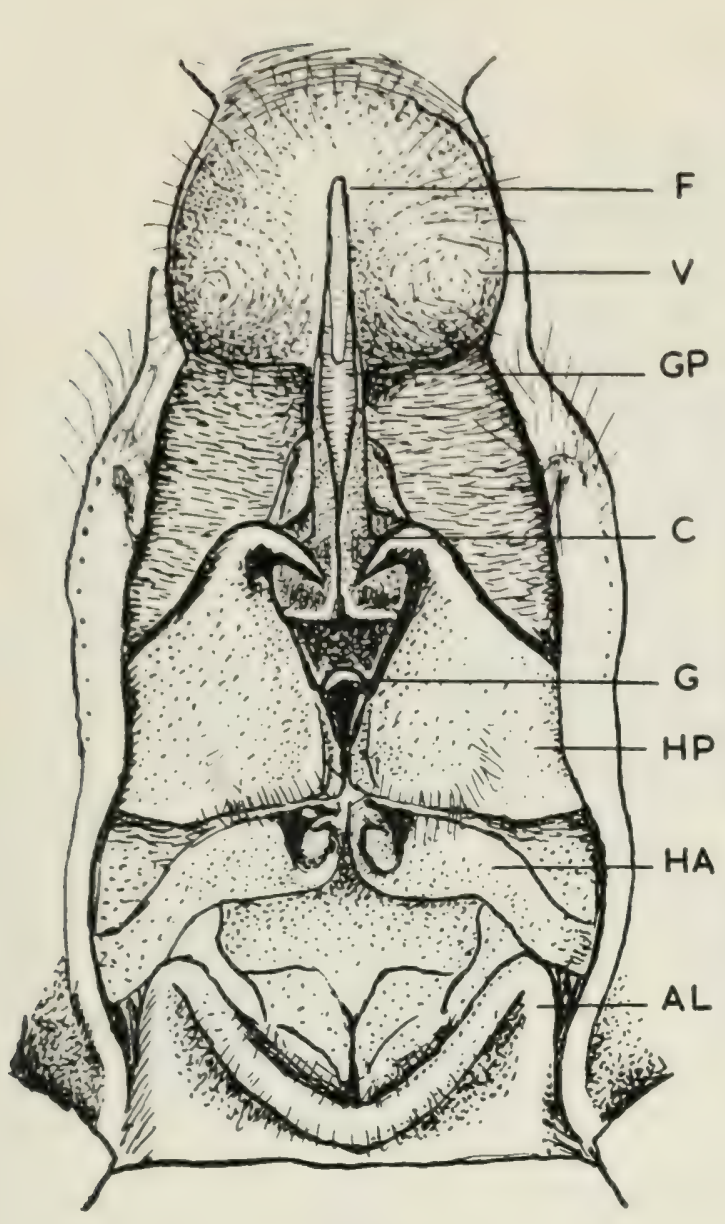

I.

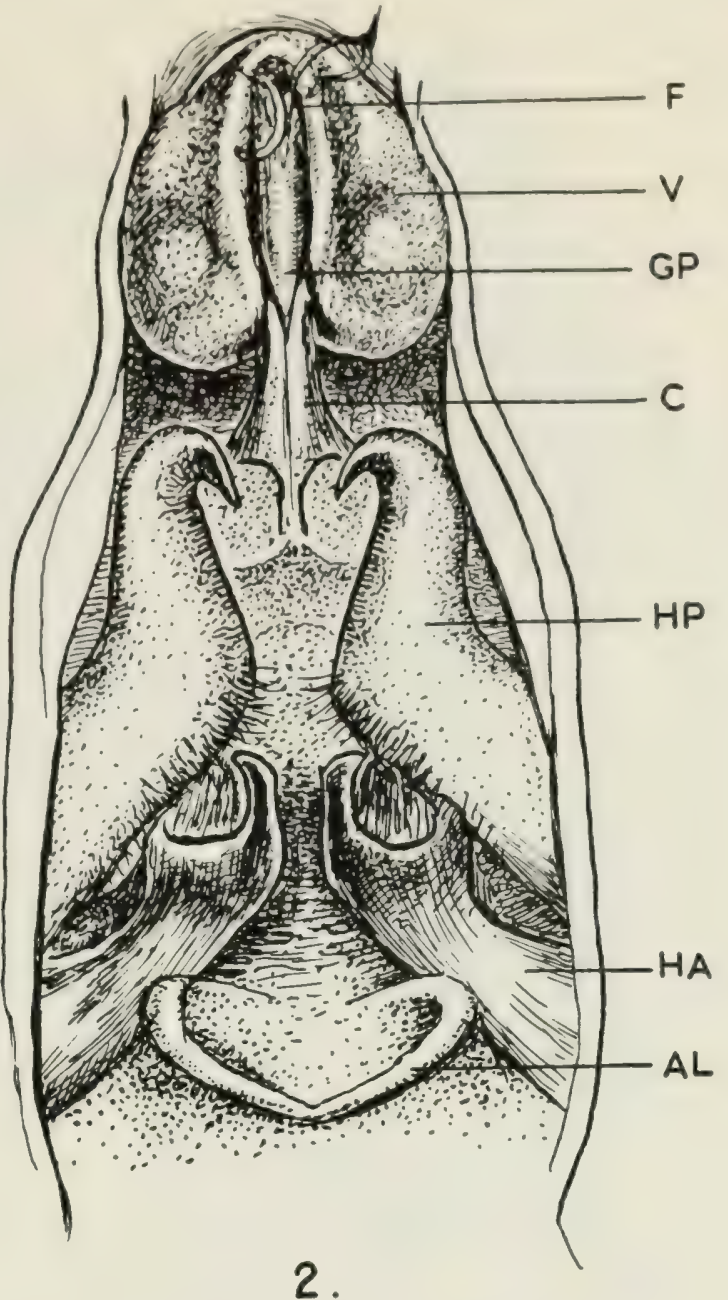

2.

Plate VI. Male genitalia in situ: 1. Gomphus exilis; 2. spicatus.

front and behind, and more heavily sclerotized. The two flagella are separate and the hood is of the cleft-pyramidal type and very hairy. The prepuce is slender and acute, suggesting a spine rather than a pouch. This feature is more marked in G. vastus than in G. fraternus. The tubular part of the glans is entirely covered by the sclerotized plates, which in Gomphus are restricted to the extreme base.

Subgenus Arigomphus (Pl. VII:2). In this subgenus the penis is essentially like that of Gomphurus. There are, however, two variations of this type of penis. One variation may be represented by G. villosipes, the other by G. furcifer. In villosipes (Pl. II:6) both the tubular and the open parts of the glans are very short and not separable by any difference in sclerotization, but the flagella are excessively long, stout at base, where the lateral wall extends for a considerable distance in the form of a ridge, and very slender toward the distal ends. In G. furcifer (Pl. II: 5), on the other hand, the tubular section is extremely long and the united walls are strongly sclerotized for the greater part of their entire length, the free flagella being extremely short. The sclerotized roof of the tube terminates in a pair of projecting points. The 

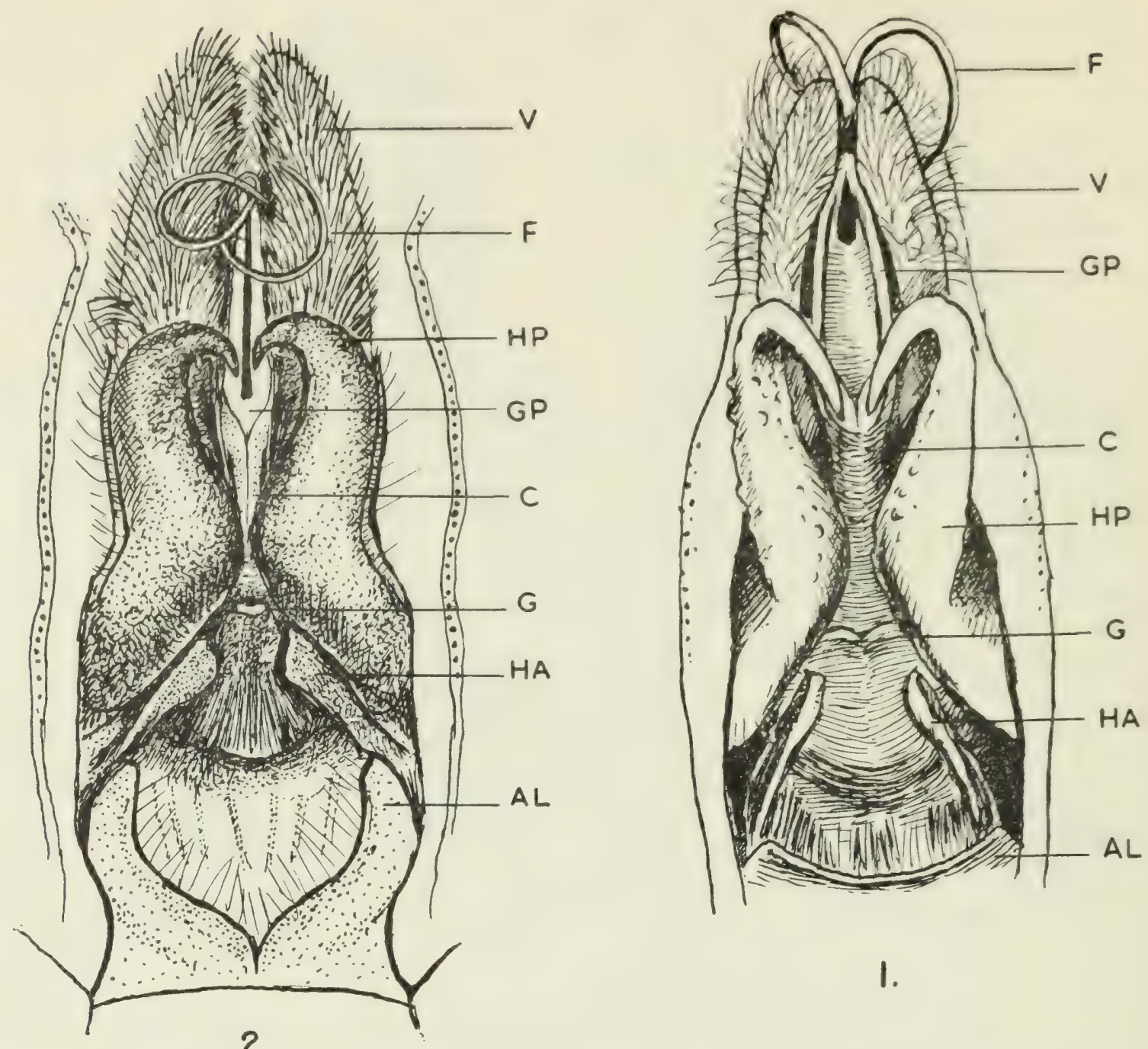

I.

Plate VII. Male genitalia in situ: 1. G. villosipes; 2. Gomphus fraternus.

prepuce in Arigomphus is unlike that of Gomphurus, being rounded and pouch-like as in the other subgenera. The hairs of the cleftpyramidal hood are softer than is usual in Gomphurus.

Subgenus Stylurus (Pl. II:1; V:2; VIII:2). In all the species of this group the penis is typical of the short form and the hood is of the split-loaf type, with the single exception of $G$. intricatus, in which the posterior part of the hood is short and somewhat concave, instead of being convex. In other respects the hood is as usual and the concavity of its rear surface must be regarded as a secondary modification of the split-loaf type.

In other respects Stylurus has very pronounced characters of its own.

The most primitive type of vesicle appears to be the bilobate type. It is found only in Gomphus and Hylogomphus, and it grades into both of the other two types. Thus, on the one hand, it grades into the split-loaf type by such a series as spicatus (bilobate), exilis (inter- 

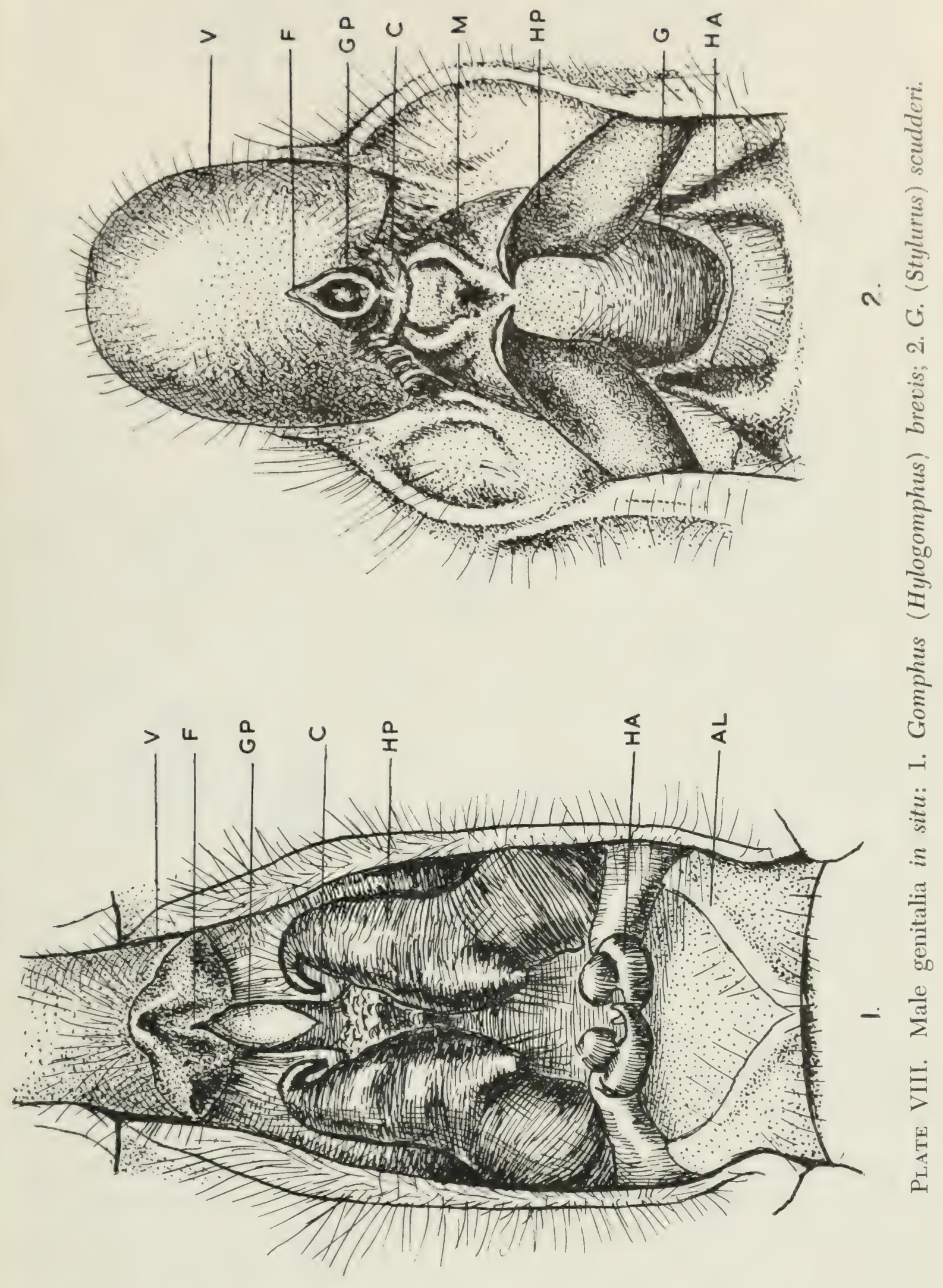
mediate), lividus (split-loaf with lateral pouches), graslinellus (splitioaf, all within the subgenus Gomphus. On the other hand spicatus or descriptus (bilobate) leads through borealis (imperfectly cleft-pyramidal with features of the bilobate type) to the completely cleft-pyramidal type, as in the subgenera Gomphurus and Arigomphus.

\section{The Hamules}

Besides the penis and vulvar lamina the hamules are an important part of the external genitalia to consider in a phylogenetic problem of this kind. As with the other characters the hamules are verv variable within the subgenus Gomphus, but are much more uniform within the other subgenera.

The posterior hamules are always the larger pair, usually much the larger. In most of the species of Gomphus s.s., all of Hylogomphus, Arigomphus and Gomphurus, they are stout at their bases, curve rearward bending toward one another near the middle, and finally, curving forward in a short spiral, terminate in a stout hook. Usually the anterodorsal margins of the two posterior hamules meet and are contiguous at the median line by the meeting of the so-called shoulders, each of which is an angular process of the hamule.

In Gomphus s.s., some species such as exilis and graslinellus have prominent shoulders and the usual sort of distal hook. In G. spicatus the shoulder is less prominent but is distinct enough; in borealis the shoulder has disappeared but the usual curvature remains, although the terminal hook is small. In G. descriptus, lividus and quadricolor the posterior hamules are narrower at base, straighter and more nearly upright and entirely lacking in shoulders. The terminal hook tends to become reduced to a small one-sided point, producing what has been called the "penguinoid type."

The anterior hamules reach their largest size in the subgenus Gomphus. In G. lividus (Pl. IX:7) they are more than three-fotirths as high as the posterior pair. The middle part is widened and rolled into a scroll-like form with the distal end projecting mesad, like a hook or thumb. Many variations of this type are found. In G. spicatus (Pl. IX:4) the general form is similar but the thumb-like process bears several hooks; in exilis (PI. IX:3) the anterior hamules are smaller and simpler, the scroll being reduced to a single fold with two asymmetrical processes approaching one another like finger and thumb. These and others are all variations of one general type, but there are some in which the basic type is no longer recognizable. In descriptus (Pl. IX:6) and quadricolor, for example, the anterior hamules are long slender hooks, like curved probes. whereas in borealis (Pl. IX:5) they are short, blunt processes, rolled into a hollow, clavate form, with numerous spines of various lengths projecting into the cavity. In fact 

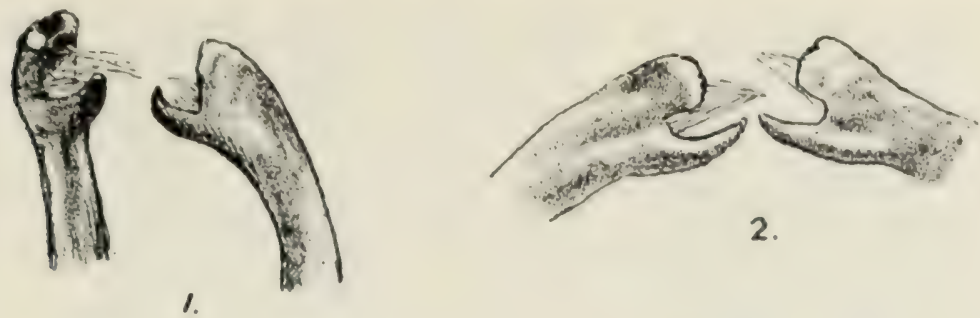

2.
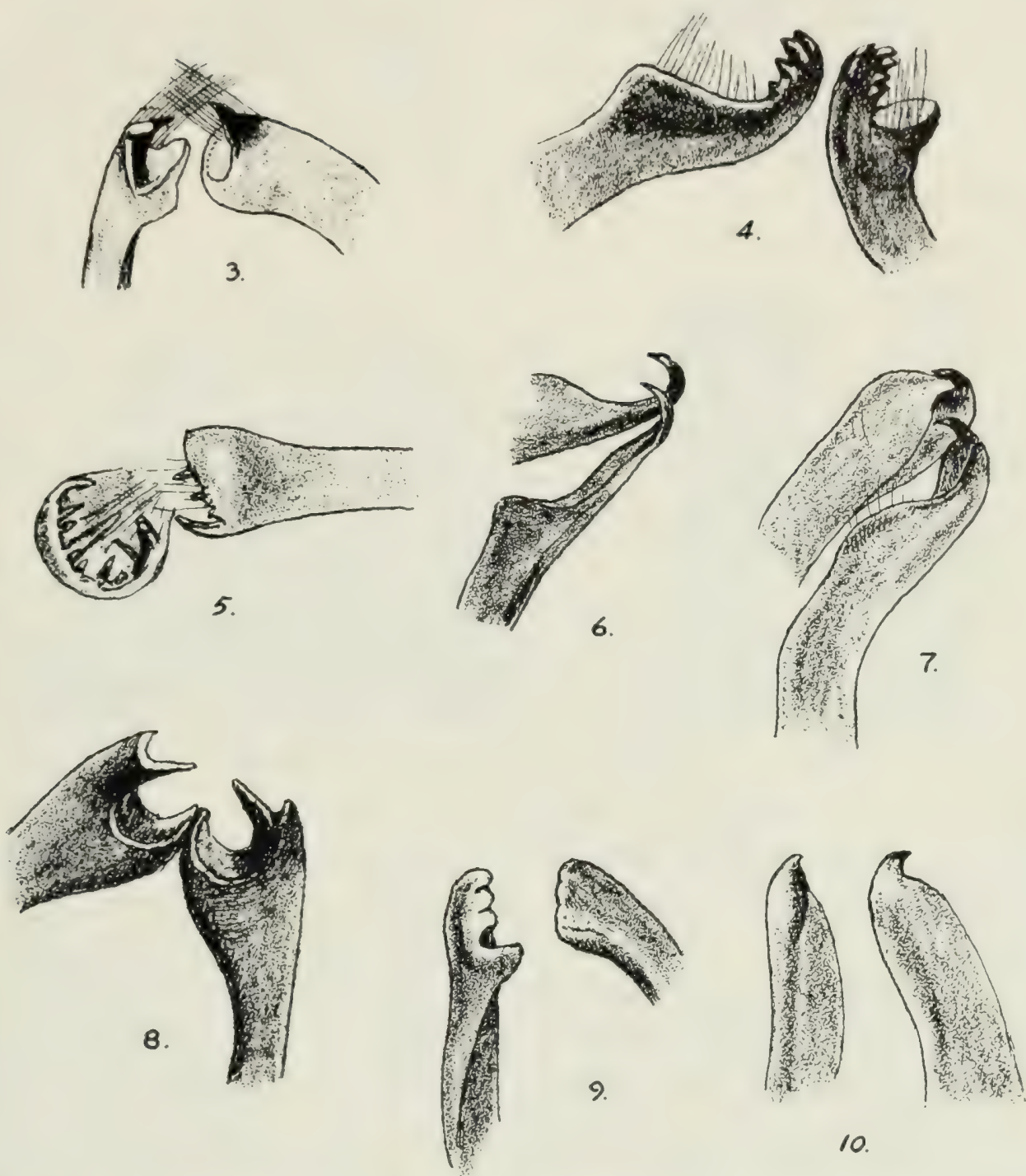

Plate IX. Anterior hamules of Gomphus: 1. vulgatissimus; 2. brevis; 3. exilis; 4. spicatus; 5. borealis; 6. descriptus; 7. lividus; 8. graslinellus; 9. fraternus; 10. villosipes.

the variety of forms of anterior hamules in Gomphus s.s. is so great that they seem to give few, if any, clues as to relationship of species.

Subgenus Hylogomphus (Pl. VIII:1). The posterior hamules are broad and backwardly curved or bent from near the base, with a very prominent shoulder and a short and abruptly reflexed terminal hook.

The anterior hamules ( PI. IX:2) are half to more than half as long as the posterior hamules, cylindrical and tubular with a blunt extremity 
bearing two or three very short processes, which oppose each other asymmetrically, the longer and more slender one suggesting a thumb.

Taken together, the hamules most nearly resemble those of Gomphurus, the anterior pair suggesting the "thumb-and-knuckles" type belonging to the latter group, the "knuckles," however, being represented by one or two knobs only.

Subgenus Arigomphus. In this group the posterior hamules lean strongly backward; the basal half is very broad with a rounded anterodorsal edge. The shoulder, although sometimes rounded, may be strongly angulate. Distally each hamule tapers to a rather slender hook, which is sometimes falciform (the "goose-neck" type of Needham).

The anterior hamuli (PI. IX:10) are much smaller and are flat, their outline suggesting a bird, the head and bill being the terminal hook.

Subgenus Gomphurus. In this large group the posterior hamules are similar to those of Arigomphus in their backward curvature and general form. They are usually somewhat stouter, however, with a shorter and more abrupt terminal hook. There is usually a pronounced shoulder, but it may be indistinct or even absent.

The anterior hamules are short and clavate, the stout distal part being rolled into a tube that is open along the posteromesal side. At the distal end there is a thumb-like process standing out at a sharp angle and several short knobs along the edge of the terminal opening, which are turned in so that they are not seen in profile view. This is the type that has been termed by Needham (1948) the "thumb-and-knuckles" type.

Subgenus Stylurus (PI. V:2; PI. VIII:2). In this group we find the greatest deviation in the form of the hamules from the usual types. The posterior hamules are narrow and usually straight and erect or bent forward. In some species they may even be curved forward or more rarely bent backward. There is no shoulder but in some species there is an angularity of the front edge that gives something of the appearance of a slight shoulder. The hamule generally terminates in a slender, nearly upright hook as in $G$. amnicola or $G$. notatus, but sometimes its apex is like the point of a curved knife.

The anterior hamules have lost the appearance of functional structures, being reduced to small slender rods without hooks or spines, which tend to lean backward between the posterior hamules and are thus often difficult to see.

FEMALE GENITALIA

These are represented by the vulvar lamina only. This is a bifid extension of the sternum of segment 8 , beneath that of segment 9 . It is usually less than half as long as the sternum of segment 9 and only 

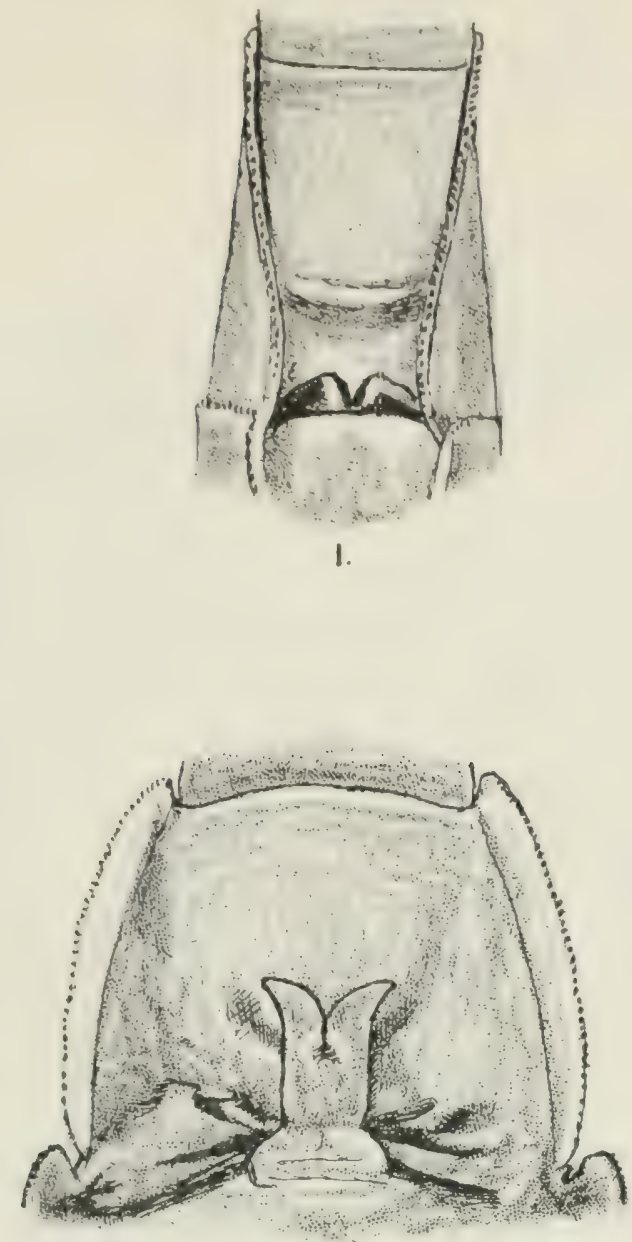

3.
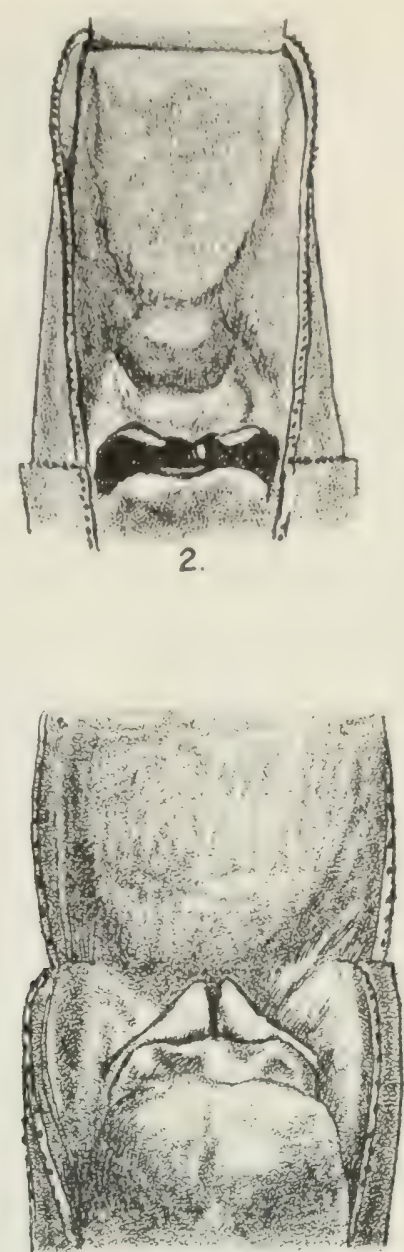

4.

Plate X. Vulvar laminae. 1. G. (Gomphus) grastinellus; 2. G. (Gomphus) lividus; 3. G. (Gomphurus) fraternus; 4. G. (Stylurus) scudderi.

rarely reaches the end of this sternum. On the other hand it is often so short as to be vestigial. It is usually flat and only rarely arched. It may be divided almost to the base, or the median notch may be less than half that length. It varies in width from a mere slit to a very obtuse notch.

In the subgenus Gomphus there are two forms of vulvar laminae, apparently correlated with the two types of penis. In those with the short type $(\mathrm{Pl} . \mathrm{X}: 1,2)$ the vulvar lamina is generally very short, the width of each lobe or half lamina being usually twice or more than twice its length. The lobes are thus very obtuse, often rounded. In those species with the long type of penis the vulvar lamina (Pl. XI:1,2) is at least one-fourth as long as the sternum of segment 9, generally one-third or more, and each lobe is longer than wide, with the apices acute. The median notch is also acute.

Of Hylogomphus I have seen the vulvar lamina of three species onlv. In brevis (PI. XI:4) it is half as long as the sternum of segment 9 with the deeply divided rami close together and decidedly arched. In 


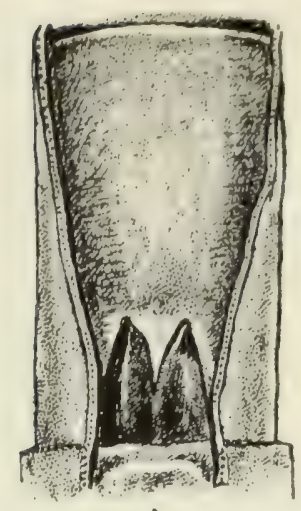

1.

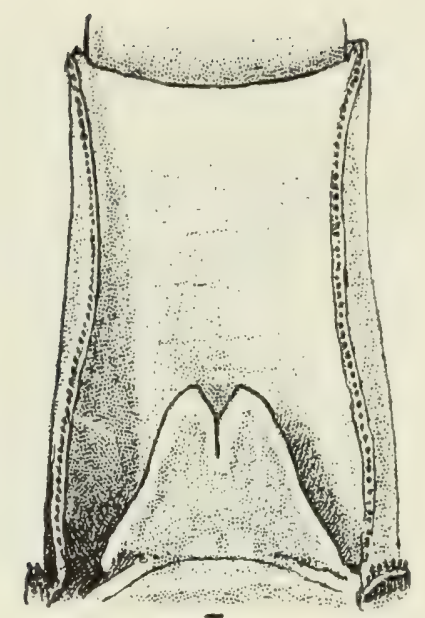

3.
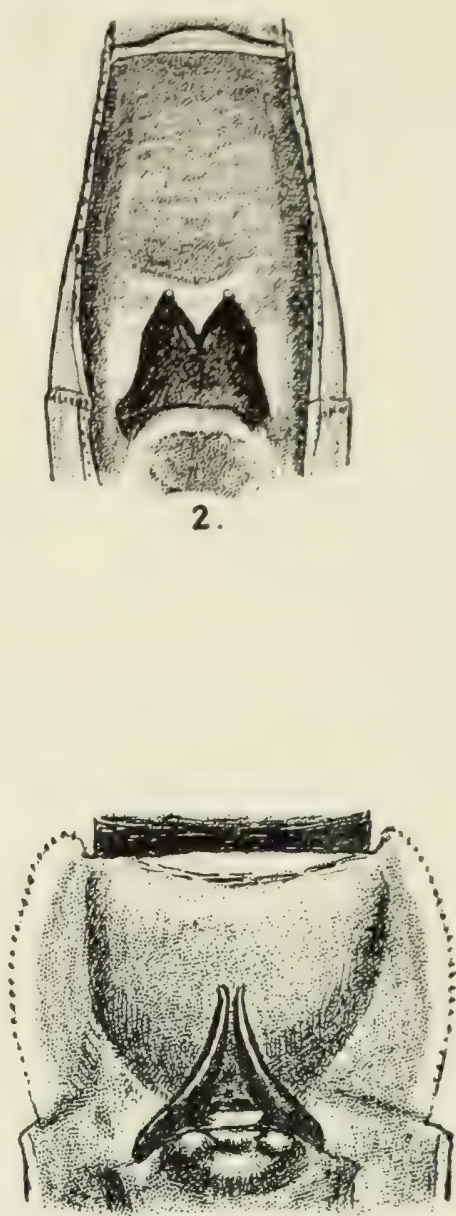

4.

Plate XI. Vulvar laminae. 1. G. (Gomphus) spicatus; 2. G. (Gomphus) descriptus; 3. G. (Arigomphus) furcifer; 4. G. (Hylogomphus) brevis.

viridifrons the lamina extends the entire length of the ninth segment, with the apices diverging as in Gomphurus. In abbreviatus, however, the vulvar lamina is less than half as long as the ninth sternum and there is a wide notch between the rami, which are hardly divergent.

The vulvar lamina of Gomphurus (Pl. X:3) is very different from those of other subgenera of Gomphus, except Hylogomphus, which approaches it to some extent. It is usually half, or more than half, as long as the sternum of segment 9, contracted beyond the base and often parallel-sided in the middle, with the apices divergent.

In Arigomphus ( $\mathrm{Pl}$. XI:3) the vulvar lamina is a flat triangular plate, less than half as long as the sternum of segment 9 and about as wide as long, with the sides slightly rounded and the apex divided by a narrow and rather short notch. This lamina is most like that of the species of Gomphus s.s. in which the penis is of the long type.

In Stylurus (PI. X:4) the vulvar lamina is like that of the other species of Gomphus s.s., in which the penis is of the short type. In other 
words it is composed of two very short projections from the hind margin of segment 8 , ustrally separated by a wide obtusingular notch, although sometimes there are slender, though short, apical points.

\section{General Discussion and Conclusions}

Basing our views mainly on the genitalia but taking other characters into consideration, we would picture the main subdivisions of the genus Gomphus and their interrelationships, as represented in North America, as follows.

The subgenus Gomphus, as characterized by Needham, is a composite group of species of rather inconspicuous appearance, owing to their prevailing dull coloration and little development of the abdominal "club)." In spite of this similarity in general appearance there are striking differences in the genitalia, which at first sight suggest that Gomphus s.s. is not an assemblage of related species at all. But on further investigation we find so much intergradation between different variations of the same organ in different species, that it seems impossible to make a satisfactory division into minor groups. Moreover the uniformity in nymphal characters is so great that in some cases the nymphs of species whose adults would appear to belong to different groups cannot even be distinguished specifically.

In this group are found the beginnings of many of the features that become highly specialized characteristics in other subgenera. In fact manv of the specialized features of the other subgenera find their prototypes in the subgenus Gomphus. Thus, although Gomphus, as a subgenus, seems well-nigh impossible to define, it is the group to which we must turn in order to find any light on the relationships of other groups.

In the majority of species of Gomphus s.s. the penis belongs to the short type, but there are a few species in which the long type appears in several stages of development, including one ( $G$. exilis) that is virtually an intermediate. It is such facts as these that make division into groups so difficult and unsatisfactory. The large, well-developed anterior hamule is probably an early feature of Comphus s.s., since these organs appear to be more or less reduced in all the other subgenera, but the extreme variability of the hamules limits considerably their value in phylogeny.

A small group of five or six species, recently given subgeneric rank by Needham (1955) is Hylogomphus. In respect of the male genitalia it is perhaps even more primitive than Gomphus s.s., inasmuch as it is the only group in which the short type of penis is combined with the bilobate tvpe of vesicle. The vulvar lamina in some of them (brevis and viridifrons) is longer than in any other group except Gomphurus. The species are stockier than those of Gomphus s.s. and the abdominal 


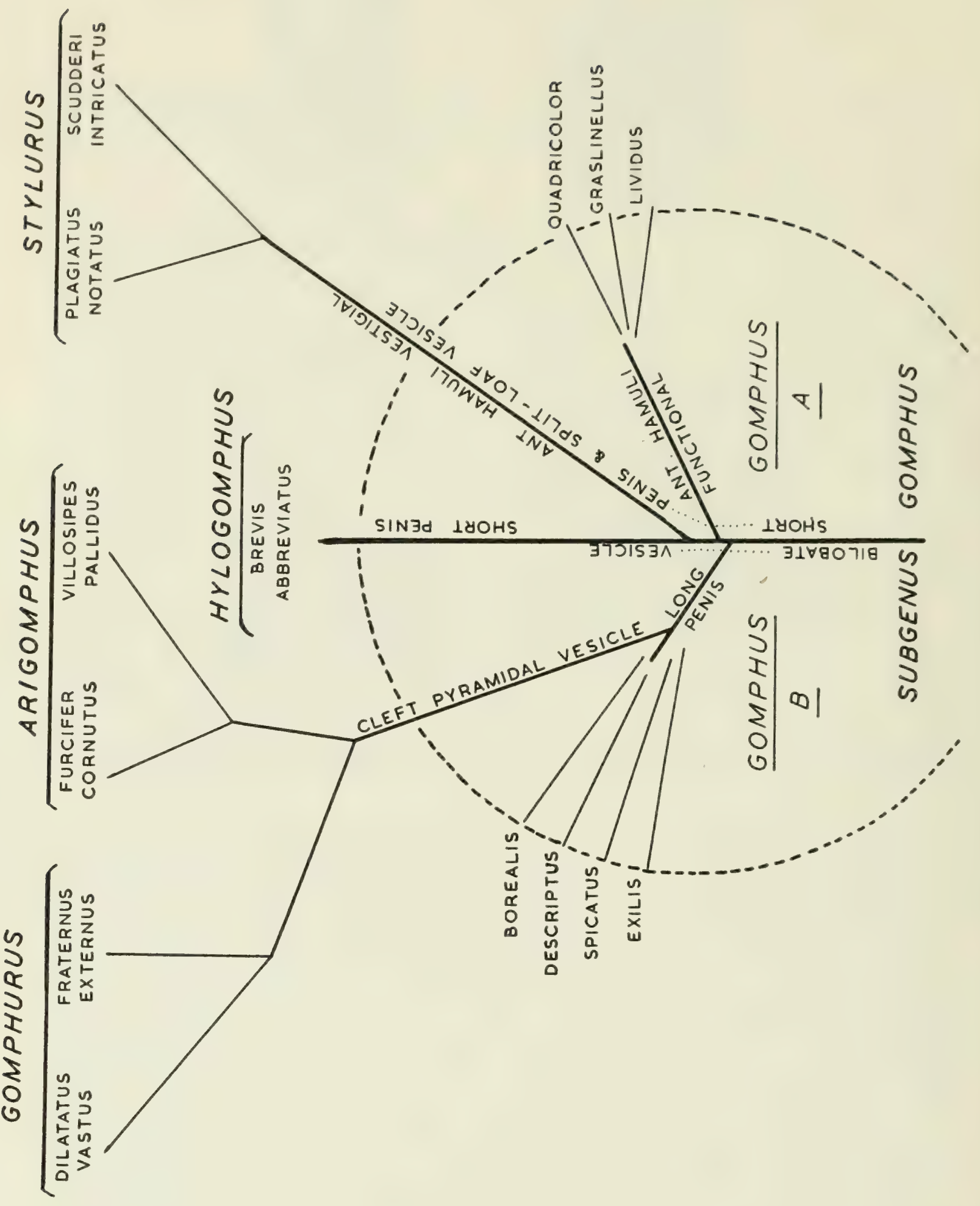


club is wider. The nymphs are also unlike Gomphus s.s., resembling Gomphurus more closely. This group seems to be not directly related to any of the other subgenera, being perhaps an earlier offshoot of the main stem of the genus.

One other specialized subgenus has retained the short penis and split-loaf vesicle, the subgenus Stylurus. In these characters Stylurus is quite similar to such species of Gomphus s.s. as confraternus, quadricolor or licidus. All three of these are suggestive of Stylurus also in the posterior hamules, which lack the usual shoulder and tend to acquire an erect position. The very short vulvar lamina in this group, as in Stylurus, supports the view that Stylurus has had its origin in similar species of this group.

Stylurus has been given generic rank by most recent authors and certainly appears to deserve this rank if judged by its relationship to other American Gomphidae only. But it is not so easily separated from the European species of Gomphus, which appear to form a natural group. Of this group $G$. flavipes Charp. seems to be definitely a Stylurus and the recently described G. ubadschii Schmidt is stated by Schmidt (1953) to be a close relative of flavipes and is easily recognized as a Stylurus by Schmidt's figures (Schmidt 1954, p. 248, Abb. 2a). But the other European species of Gomphus, especially G. pulchellus Selys, and G. simillimus Selys do not appear to belong to Stylurus and are yet too close to G. flavipes to be generically distinct.

This matter needs careful study before we can be justified in giving generic rank to Stylurus.

The other two specialized subgenera, Gomphurus and Arigomphus, have in common the long type of penis, including the cleft-pyramidal hood. Arigomphus is nearest Gomphus s.s. in form of body, slight development of the abdominal club, characters of vulvar lamina and general form of nymph. The vulvar lamina is particularly like those of the species of Gomphus s.s. that possess the long type of penis, only slight differences separating them. They are particularly like $G$. spicatus, which was at one time included in Arigomphus.

The species of Gomphurus have a distinctive appearance, which is unmistakable: the sturdy thorax and basal abdominal segments, the comparatively slender middle abdominal segments of the male, and the broad expansion of segments seven to nine in both sexes, terminated by a very small tenth segment and anal appendages. The colour pattern is also striking as a rule, the dark markings contrasting with the yellow green more strongly than usual. The only species outside the Gomphurus group that has a comparable abdominal club is $G$. (Stylurus) scudderi, but here the resemblance is wholly superficial. The anterior hamules of Gomphurus, which are the "thumb-andknuckles" type are peculiar to this subgenus, although approached by Hylogomphus and one species of Gomphus s.s., namely G. borealis 
Ndm. The nymphs are unlike those of Gomphus s.s. in general form and in the very small segment 10 of the abdomen, but are approached by Hylogomphus.

The relationships that we have discussed may be summed up in the accompanying phylogenetic tree. It shows the affinities believed to exist between the subgenera of Comphus and suggests their paths of descent from various sections of the primitive subgenus Gomphus, this group being considered most nearly related to the ancestral parent stock of the entire genus as represented in North America. Where a subgenus is further divisible the main divisions are shown but no attempt has been made to indicate the interrelationships of species, except in the case of a few of the key species of Gomphus s.s. (“Gomphus B”).

\section{ABBREVIATIONS USED ON PLATES}

AL-anterior lamina; C-collar; D-diverticulum; F-flagellum; G-guard; GP-glans penis; HA-anterior hamule; $\mathrm{HP}$-posterior hamule; $\mathrm{M}$-median segment of penis; $\mathrm{O}$-orifice of penis; $\mathrm{PR}$-prepuce; $\mathrm{S}$-stem of penis; $\mathrm{SH}$ - "shoulder"; ST-sternum of abdominal segment 3; V-hood of vesicle.

\section{REFERENCES}

Fraser, F. C.

1940. A comparative study of the penes of the family Gomphidae. Trans. R. Ent. Soc. London, 90, part 20: 541-550.

NeEdham, J. G.

1887. Preliminary studies of N. American Gomphinae. Can. Ent., XIX: 164-168.

1901. Aquatic Insects in the Adirondacks. N. Y. State Mus. Bull. 47, Odonata, pp. 429-540.

1948. Studies on the North American Species of the Genus Gomphus. Trans. Amer. Ent. Soc. 73: 307-339 with PL. XV and text figure.

Needham, J. G., and M. J. Westfall, Jr.

1955. A Manual of the Dragonflies of North America. Univ. of Calif. Press.

SCHMIDT, ERICH.

1953. Zwei neue Libellen aus dem Nahen Osten. Mitteil. Münch. Entom. Gesell. e. V. 43:1-9.

1954. Die Libellen Irans. Ergebn. der Oesterreich. Iran-Exped. 1949/1950, pp. 223-260.

Tillyard, R. J.

1917. The Biology of Dragonflies. Univ. Press, Cambridge. 



6.6.

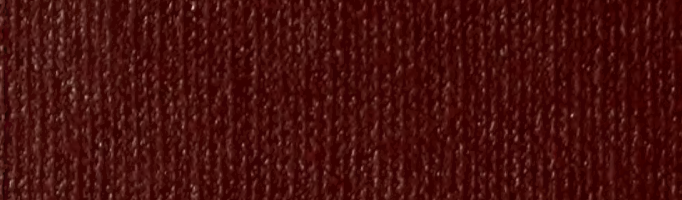

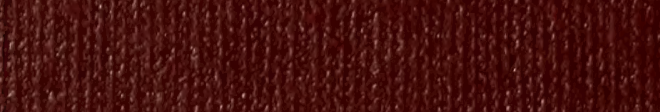

W67.

(1710)

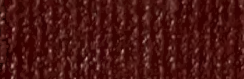

(2)

(1)

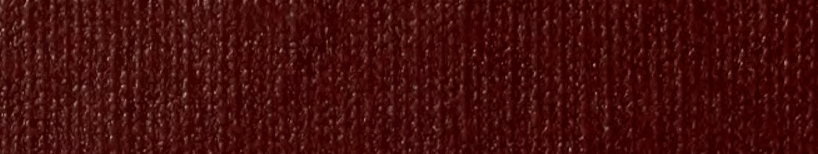

14.6)

9.

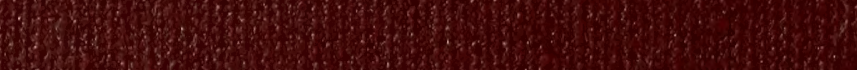

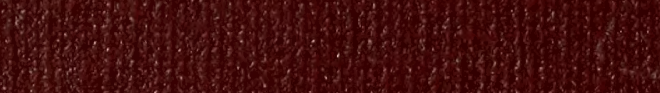
(1) 